\title{
Anchoring the snare tip by means of a small incision facilitates en bloc endoscopic mucosal resection and increases the specimen size
}

Endoscopic mucosal resection (EMR) allows curative resection of superficial colorectal neoplasms up to $2 \mathrm{~cm}$ in diameter. En bloc resection is generally not possible for larger lesions and for some smaller very flat lesions because of the difficulty in capturing them appropriately [1]. Piecemeal EMR is possible for larger colonic lesions, but carries a high risk ( $20 \%)$ of recurrence [2]. Hybrid procedures, involving use of an endoscopic submucosal dissection (ESD) device to make mucosal incisions around the lesion, have been proposed for the colon, to increase the lesion size for which en bloc snare resection is possible, and to achieve snare resection in all cases of very flat lesions. However, in the colon, ESD is particularly technically challenging [3], and mucosal incision can be quite time-consuming and risky in nonexpert hands in this location because of the folded anatomy and the bowel movement. Moreover the ESD devices are expensive, with no specific reimbursement in most European countries.

We here propose a new, simple, and reproducible maneuver to facilitate colonic mucosal resection. In the case of large $(2-3-\mathrm{cm})$ colonic polyps ( $\mathbf{F i g . 1}$, - Video 1) or very flat lesions (\$ Fig. 2 , - Video 2), after submucosal injection, we have made a small $(0.2-\mathrm{mm})$ incision at the distal part of the lesion, using the tip of the snare with an endocut current. This incision allows anchoring of the snare tip and thereby opening of the snare in a circular shape. This method holds the snare in place and avoids slippage during the resection. Moreover, the circular opening allows a larger re- section. We currently use this trick for borderline lesions (approximately $2 \mathrm{~cm}$ ) or very flat lesions in the colon, and no complications due to the small incision have been observed. This method is useful in cases of difficult or very flat lesions,
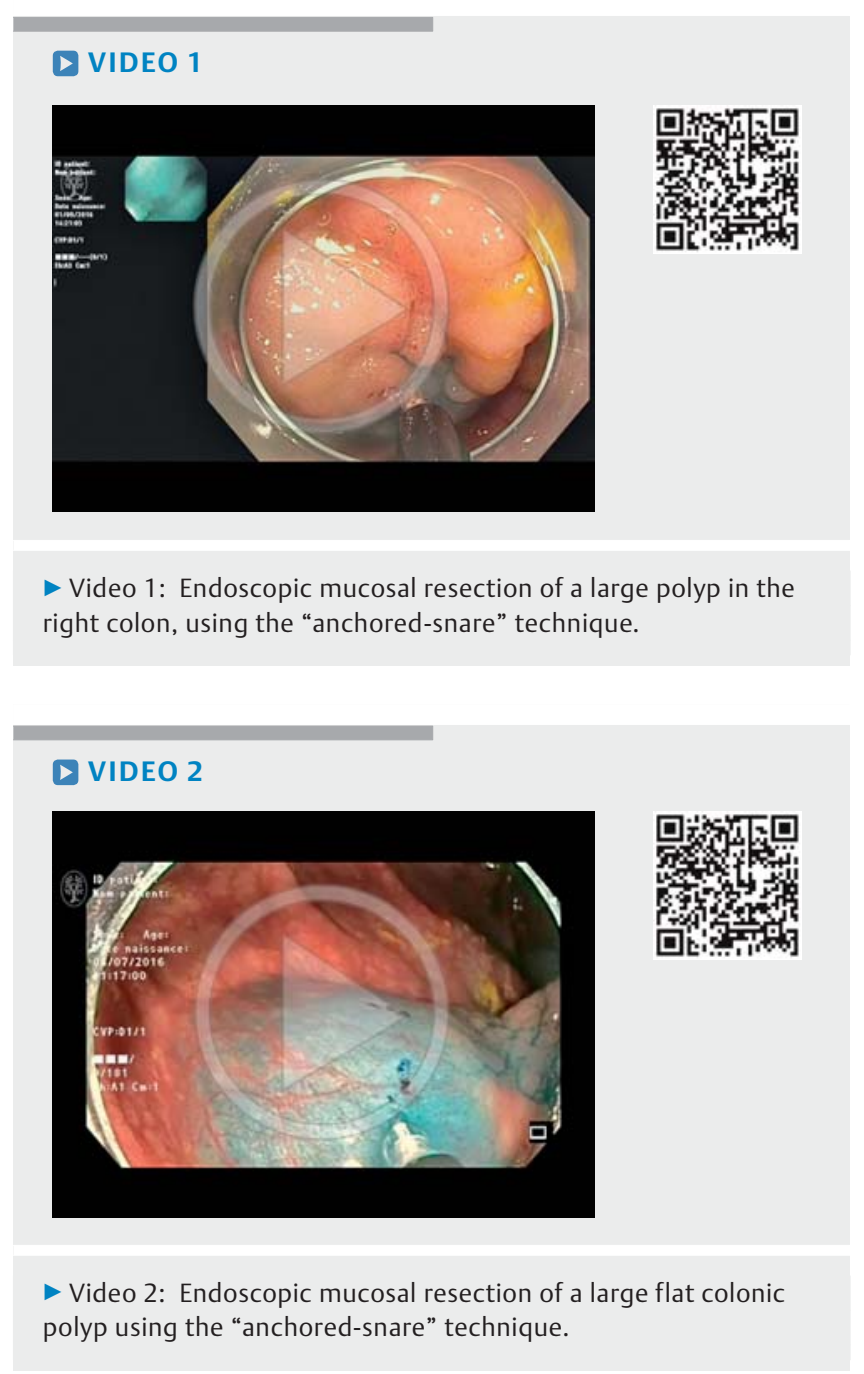
disease.

or large colonic polyps, for increasing the en bloc resection rate, allowing higher quality pathological analysis, and decreasing the risk of residual or recurrent 

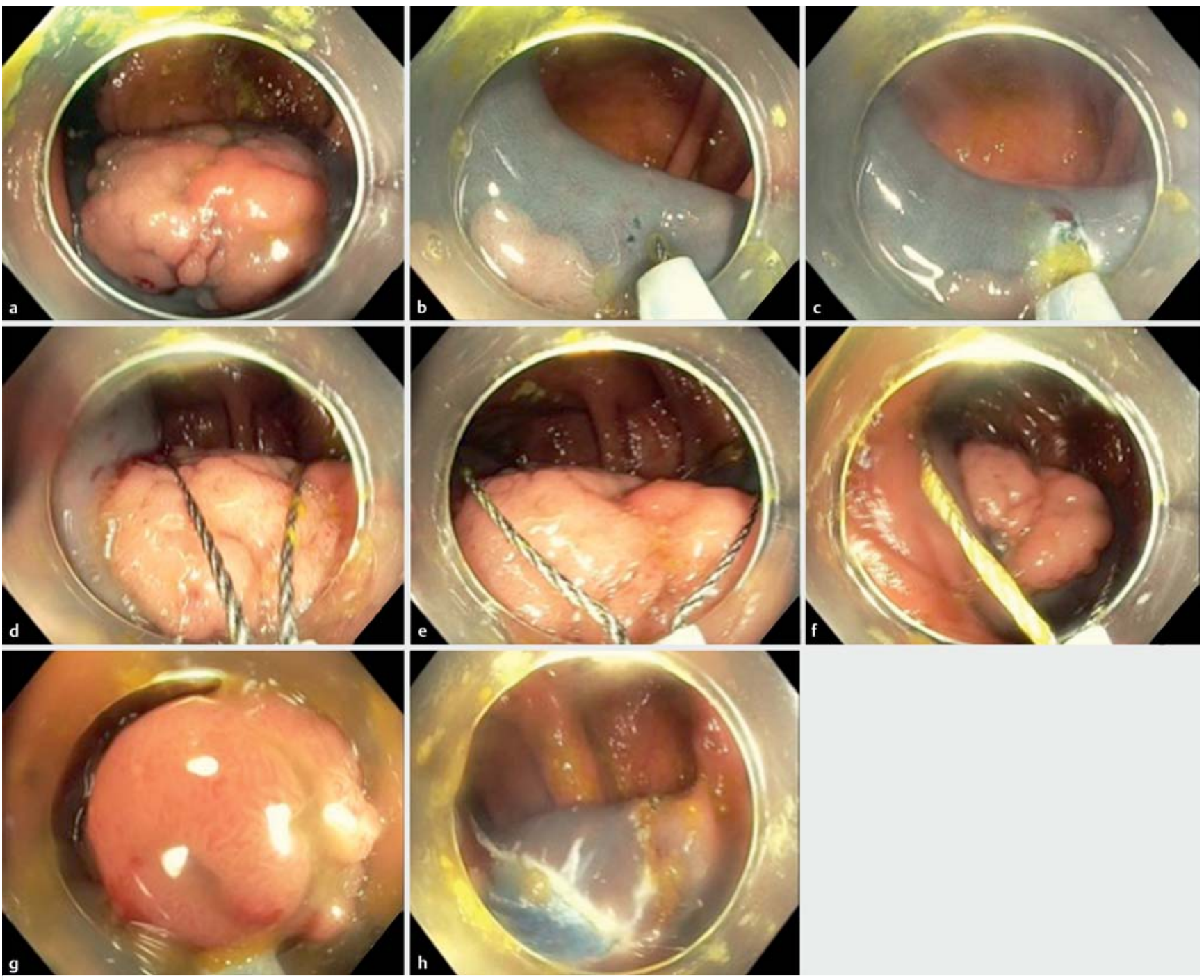

- Fig. 1 Endoscopic mucosal resection of a large polyp in the right colon, using the "anchored-snare" technique. a Large colonic polyp after submucosal injection. b, $\mathbf{c}$ Small incision with the tip of the snare using an endocut current. $\mathbf{d}-\mathbf{f}$ Large circular opening of a $25-\mathrm{mm}$ snare, enabled by the anchoring of the tip of the snare. $\mathbf{g}$ En bloc capture of the entire large polyp. $\mathbf{h}$ Macroscopic complete resection (mucosal defect).

Endoscopy_UCTN_Code_TTT_1AQ_2AD

\section{Competing interests}

The authors have no competing interests to disclose.
The Authors

Jérémie Jacques ${ }^{1}$, Romain Legros ${ }^{1}$, Aurélie Charissoux $^{2}$, Jérôme Rivory ${ }^{3}$, Thierry Ponchon $^{3}$, Denis Sautereau ${ }^{1}$, Mathieu Pioche ${ }^{3}$

1 Department of Gastroenterology and Digestive Endoscopy, CHU Dupuytren, Limoges, France

2 Department of Anatomopathology, CHU Dupuytren, Limoges, France

3 Digestive Endoscopy Unit, Department of Gastroenterology, Pavillon H, Hôpital Edouard Herriot, Hospices Civils de Lyon, France
Corresponding author

\section{Jérémie Jacques, MD}

Service d'Hépato-gastro-entérologie, $\mathrm{CHU}$ Dupuytren, 87042, Limoges, France Fax: +33-5-55058733

jeremiejacques@gmail.com 

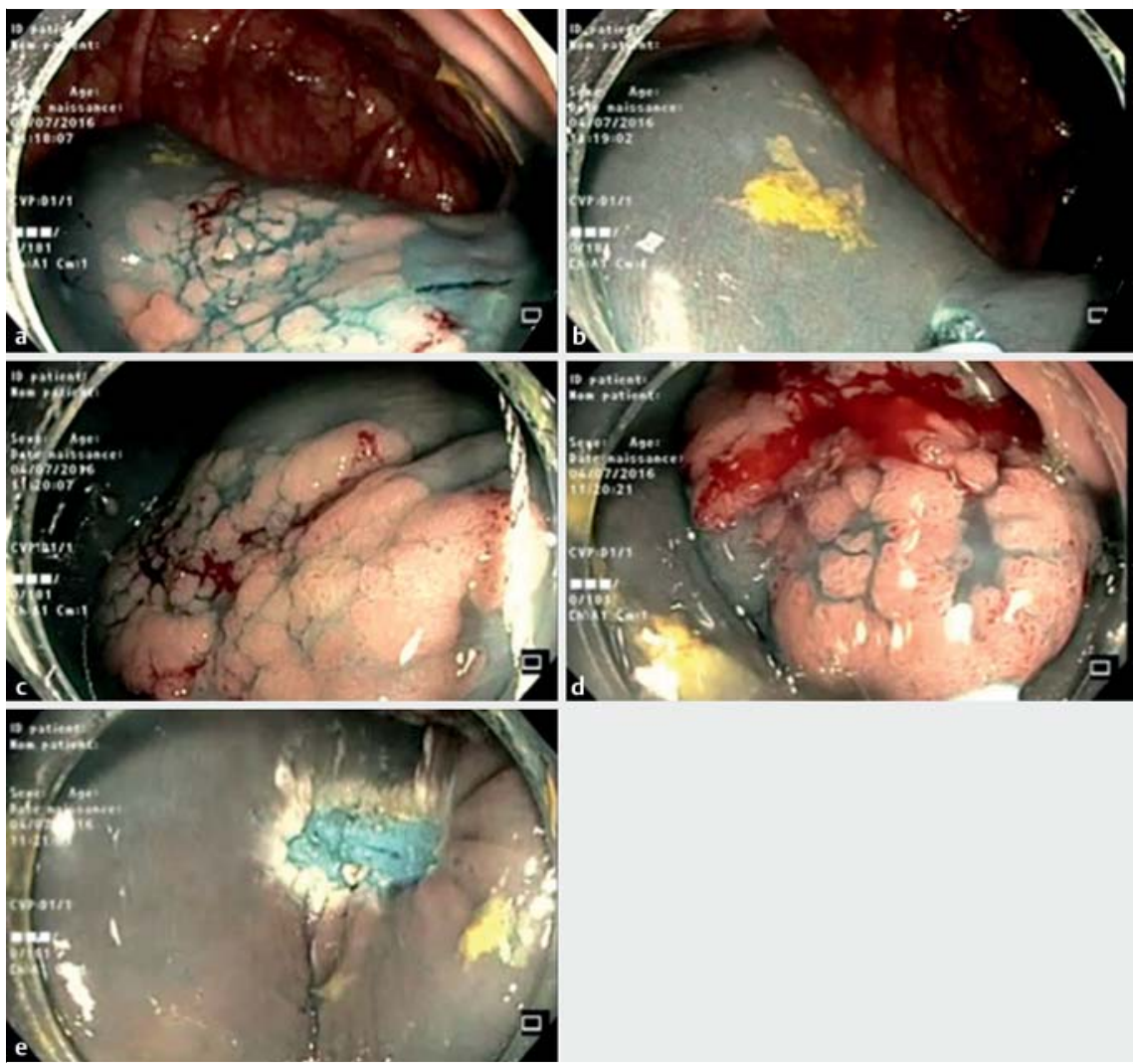

- Fig. 2 Endoscopic mucosal resection of a large flat colonic polyp using the "anchoredsnare" technique. a Large flat colonic polyp after submucosal injection. b Small incision with the tip of the snare using an endocut current. c Large circular opening of a $25-\mathrm{mm}$ snare, enabled by the anchoring of the snare tip. $\mathbf{d}$ En bloc capture of the entire large flat polyp. e Macroscopic complete resection (mucosal defect).

[1] Bourke M. Current status of colonic endoscopic mucosal resection in the west and the interface with endoscopic submucosal dissection. Dig Endosc 2009; 21: 1 -6

[2] Moss A, Bourke M], Williams S] et al. Endoscopic mucosal resection outcomes and prediction of submucosal cancer from advanced colonic mucosal neoplasia. Gastroenterology 2011; 140: 1909-1918

[3] Saito Y, Sakamoto T, Nakajima T et al. Colorectal ESD: current indications and latest technical advances. Gastrointest Endosc Clin N Am 2014; 24: 245 - 255

\section{Bibliography}

DOI http://dx.doi.org/10.1055/s-0042-121009

Endoscopy 2017; 49: E39-E41

(c) Georg Thieme Verlag KG

Stuttgart · New York

ISSN 0013-726X 